\title{
A Selenium-Catalyzed Oxidative Allylic Sulfonamidation
}

Key words

allylic amination

sulfonimidation

late-stage functionalization

selenium catalysis

terpenoids
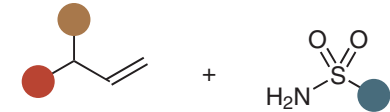

catalyst a or b (15 mol\%)

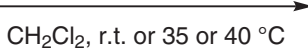

$=\mathrm{Bn}, \mathrm{Alk}, \mathrm{Ar}$

$=\mathrm{H}, \mathrm{Me}$

$=\mathrm{Ar}, \mathrm{OAlk}, \mathrm{OA}$ PIDA (2.0 equiv)
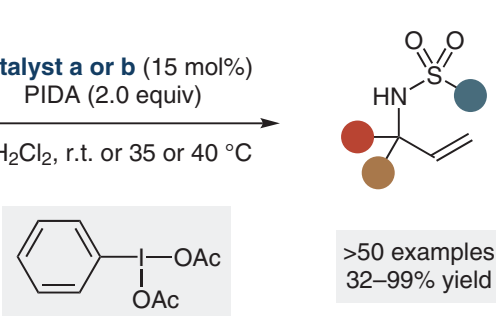

PIDA
$\mathrm{Cy}_{3} \mathrm{P}=\mathrm{Se}$

catalyst a

(electron-poor olefins)

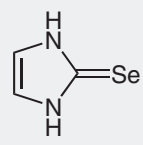

50 examples $32-99 \%$ yield catalyst b (electron-rich olefins)

Sulfonamidation of feedstock olefins:<smiles>C=CC(CCBr)N[N+](=O)[O-]</smiles>

$85 \%$ yield<smiles>C=CC(C)(NS(=O)(=O)OCC(Cl)(Cl)Cl)c1ccccc1</smiles>

$74 \%$ yield<smiles>C=CC(CCC)NS(=O)(=O)OCC(Cl)(Cl)Cl</smiles>

$81 \%$ yield<smiles>C=CC(Cc1ccccc1)NS(=O)(=O)c1ccc(N)cc1</smiles>

$84 \%$ yield

Late-stage functionalization and oxidative amination using drug-derived sulfonamides:

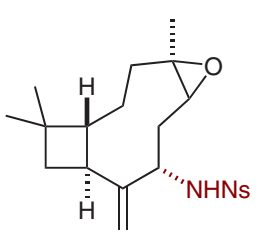

$75 \%$ yield

$$
\mathrm{dr}=10: 1
$$
from caryophyllene oxide

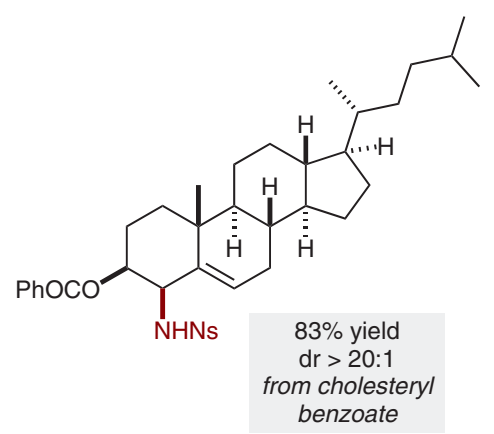

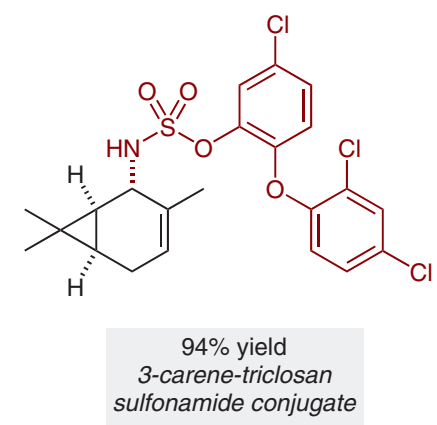

Significance: Michael and co-workers report a general catalytic metal-free allylic $\mathrm{C}-\mathrm{H}$ sulfonamidation of olefins. By analogy to selenium dioxidemediated transformations, this reaction is proposed to proceed via an imido selenium intermediate that undergoes a classical ene/[2,3]-sigmatropic shift to provide a broad variety of allylic amines in moderate to excellent yields and mostly with high regioselectivity.
Comment: Although the aza-variant of the allylic oxidation of olefins could be expected to be in no way inferior to the selenium dioxide-mediated transformation, the major limitation in the past has been the involvement of highly explosive anhydrous chloramine T. By introducing phosphine selenides (catalyst a) or selenoureas (catalyst b) as precursors for the relevant catalytic imido selenium intermediate in combination with (diacetoxyiodo)benzene (PIDA) as a readily available oxidant, this work could lead to a renaissance in direct oxidative allylic amination reactions. 